\title{
The Role of Biofilm Exopolysaccharides on Biocontrol of Plant Diseases
}

\author{
Wafaa M. Haggag \\ Plant Pathology Department, Agricultural Research and Biology Division \\ Centre of Excellence for Advanced Science, National Research Centre
}

Egypt

\section{Introduction}

A huge variety of biopolymers, such as polysaccharides, polyesters, and polyamides, are naturally produced by microorganisms. These range from viscous solutions to plastics and their physical properties are dependent on the composition and molecular weight of the polymer. Exopolymers have been associated with the initial adhesion of microbes which is the primary step for biofilm formation. Moreover, the polymeric matrix of biofilms has a considerable influence on some of the most important physical and physiological properties of biofilms. Many microorganisms in the natural environment exist in multicellular aggregates generally described as biofilms, associated with solid surfaces and in intimate contact with other microbial cells. Cells adhere to surfaces and each other through a complex matrix comprising a variety of extracellular polymeric substances (EPS) including exopolysaccharides, proteins and DNA.

\section{Biofilm identification}

A biofilm is an aggregate of microorganisms in which cells adhere to each other and/or to a surface. In fact, archaeal, bacterial, and eukaryotic microbes produce the biopolymers. Biofilms may form on living or non-living surfaces, and represent a prevalent mode of microbial life in natural and industrial (Hall-Stoodley et al., 2004). The microbial cells growing in a biofilm are physiologically distinct from planktonic cells of the same organism, which, by contrast, are single-cells that may float or swim in a liquid medium. Biofilm cells respond to nutrient and waste product diffusion gradients, modulate their metabolism as a function of their position within the biofilm, contact adjacent cells, and engage in cell-cell communication. Microbes form a biofilm in response to many factors, which may include cellular recognition of specific or non-specific attachment sites on a surface, nutritional cues, or in some cases, by exposure of planktonic cells to sub-inhibitory concentrations of antibiotics (Karatan Watnick, 2009).

\section{Biofilm formation}

Formation of a biofilm begins with the attachment of free-floating microorganisms to a surface. These first colonists adhere to the surface initially through weak, reversible van der 
Waals forces. The first colonists facilitate the arrival of other cells by providing more diverse adhesion sites and beginning to build the matrix that holds the biofilm together. Once colonization has begun, the biofilm grows through a combination of cell division and recruitment. The final stage of biofilm formation is known as development, and is the stage in which the biofilm is established and may only change in shape and size. The development of a biofilm may allow for the aggregate cell colony(ies) to be increasingly antibiotic resistant. For example, the bacteria colonize root elongation zones and root hairs, forming dense biofilms. Microscopy of rhizobial cells within curled root hairs reveals small biofilm-type aggregates that provide the inocula for root invasion; the rhizobial cells migrate down infection threads as biofilmlike filaments towards the root interior (Figure 1) (Gage 2004). Agrobacterium tumefaciens and rhizobia can form dense, structurally complex biofilms on root surfaces, extensively coating the epidermis and root hairs, and these bacteria also form elaborate biofilms on abiotic surfaces (Figure 1b) (Ramey et al., 2004).

Microorganisms synthesize a wide spectrum of multifunctional polysaccharides including intracellular polysaccharides, structural polysaccharides and extracellular polysaccharides or exopolysaccharides (EPS). Production of exopolysaccharide is generally important in biofilm formation, and likewise can effect the interaction of microbes with roots and root appendages (Bianciotto et al., 2004). Exopolysaccharides generally constitute of monosaccharides and some non-carbohydrate substituents (such as acetate, pyruvate, succinate, and phosphate). Owing to the wide diversity in composition, exopolysaccharides have found multifarious applications in various food and pharmaceutical industries. Recent findings suggest that multiple polysaccharides modulate the chemical and physical attributes of the Pseudomonas fluoresces and P. aeruginosa biofilm matrix on abiotic surfaces (Figure 2) (Friedman and Kolter 2004). Such complexity may explain variable observations regarding the requirement for specific exopolysaccharides in biofilm formation and root association.

\section{Extracellular matrix}

These adherent cells are frequently embedded within a self-produced matrix of extracellular polymeric substance (Figure 3). EPS are biopolymers of microbial origin in which biofilm microorganisms are embedded. Contrary to common belief, EPS are certainly more than only polysaccharides. An HPLC analysis showed similar pattern in the polysaccharide production by P. polymyxa. According to stander sugar, suggesting that the biopolymer is a homopolysaccharide, which is consistent of various sugars and sugar derivatives such as glucose, galactose, mannose and xylose (Haggag, Wafaa, 2007). They comprise, in addition, a wide variety of proteins, glycoproteins, , glycolipids, enzymes,, and in some cases, surprising amounts of extracellular DNA (e-DNA) (Figure 4 and 5). In environmental biofilms, polysaccharides are frequently only a minor component (Frølund et al., 1961). Some EPS components deserve particular attention.

Alginate, a polyanion polysaccharide, is the best-investigated component of mucoid Pseudomonas aeruginosa biofilms (Figure 4). Alginate is themain Traditionally, the selfassembly processes of algal alginates were mainly used in biotechnology for encapsulation purposes but given the option of fine-tuning its material properties, bacterial alginates are more and more considered for the production of micro- or nanostructures suitable for medical applications. Representative of a family of polysaccharides that neither show branching nor repeating blocks or unit patterns and this property distinguishes it from to 


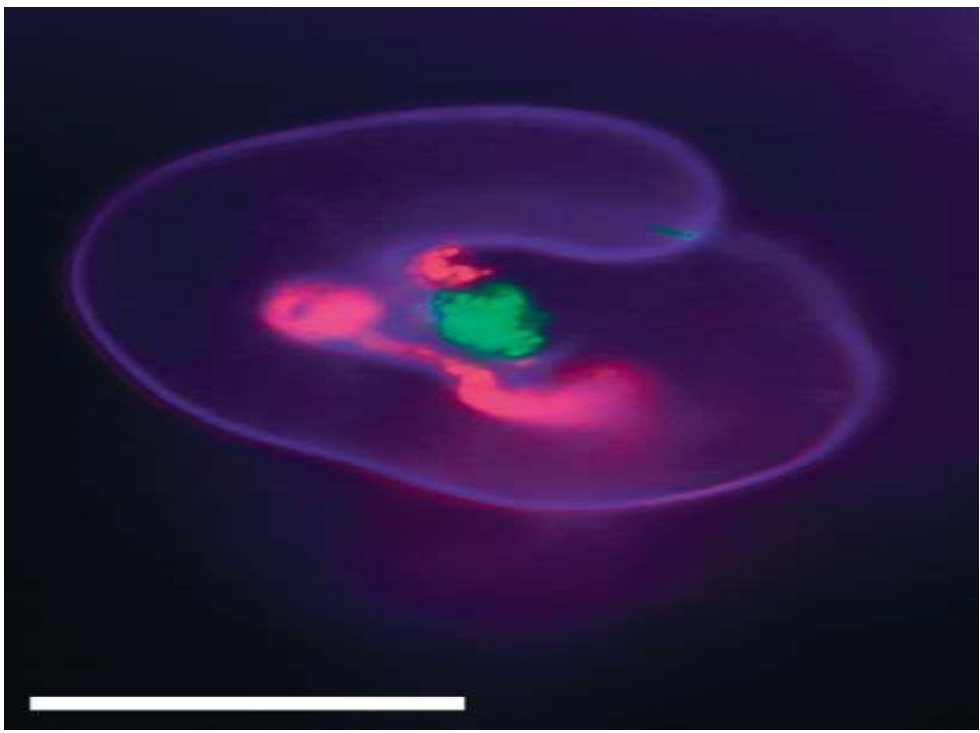

a

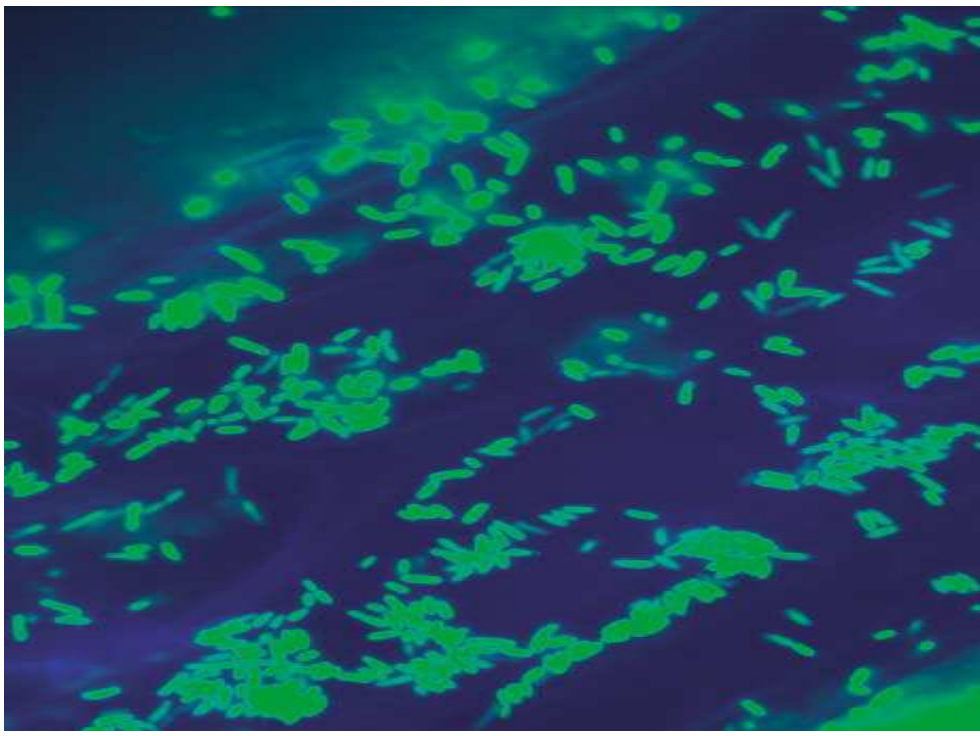

b

Fig. 1. Colonization of plants by the Rhizobiaceae. (a) Curled root hair of alfalfa with red (DsRed) and green (GFP)-expressing Sinorhizobium meliloti in a mixed microcolony occupying the interior bend of the curl. The DsRed-labeled cells have initiated an infection thread. (Image courtesy of (b) Epifluoresence micrograph of Agrobacterium tumefaciens C58 (Ptac-gfp) adhered to Arabidopsis thaliana Landsberg root segment. Overlay of gfp fluorescence and autofluorescence of plant tissue. 


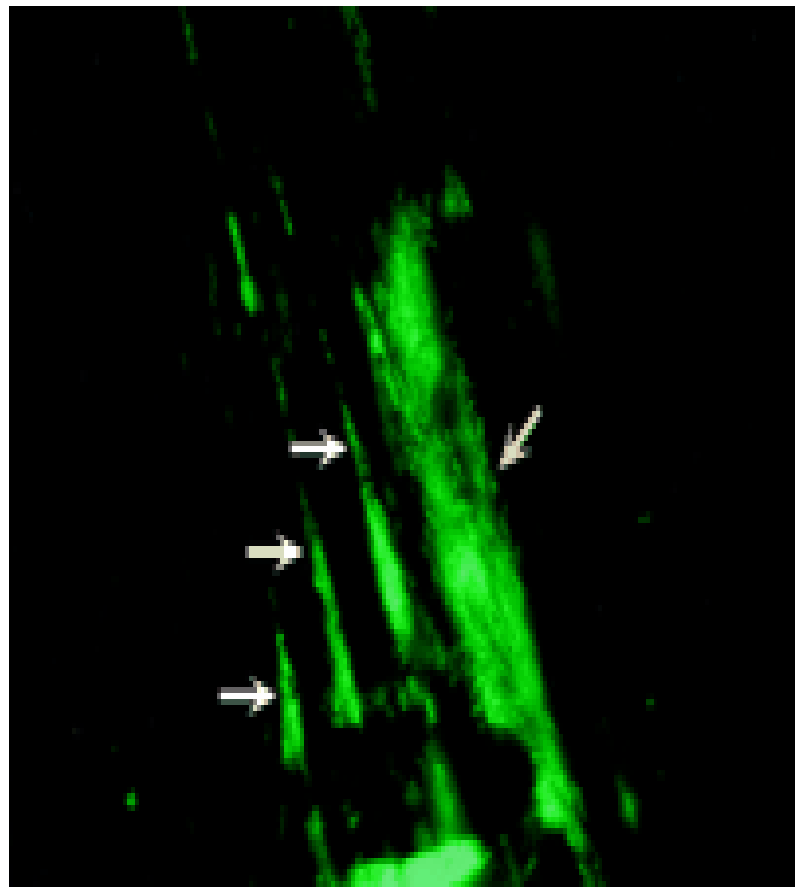

Fig. 2. Biofilm on a plant root. Biofilm of GFP-labeled Pseudomonas fluorescens WCS365 on the root of a tomato plant. A large microcolony of bacteria is apparent on the root surface and is indicated by the yellow arrow. The white arrows highlight three smaller colonies that have formed at plant root cell boundaries, which may be the site of release of root exudates used by bacteria as nutrient sources. The diffuse appearance of some bacterial cells in the large microcolonies suggests that these bacteria are covered by an EPS. EPS may play a role in formation of these microcolonies, suggesting that these communities have many of the characteristics of typical bacterial biofilms.

other polymers like xanthan or dextran. However, several recent reports have shown that other polysaccharides contribute to biofilms formed by nonmucoid $P$. aeruginosa strains, which are believed to be the first to colonize cystic fibrosis patients. A recent example is the expression of the psl operon, which is required in order to maintain the biofilm structure after attachment. Overproduction of the Psl polysaccharide led to enhanced cell surface and intercellular adhesion of $P$. aeruginosa, which translated into significant changes in the architecture of the biofilm (Ma, et al., 2006). Some biofilms have been found to contain water channels that help distribute nutrients and signalling molecules. This matrix protects the cells within it and facilitates communication among them through biochemical signals. This matrix is strong enough that under certain conditions, biofilms can become fossilized. Microbe living in a biofilm usually have significantly different properties from free-floating microbe of the same species, as the dense and protected environment of the film allows them to cooperate and interact in various ways. One benefit of this environment is increased resistance to detergents and antibiotics, as the dense extracellular matrix and the outer layer of cells protect the interior of the community. 


\section{Biofilm Analysis}

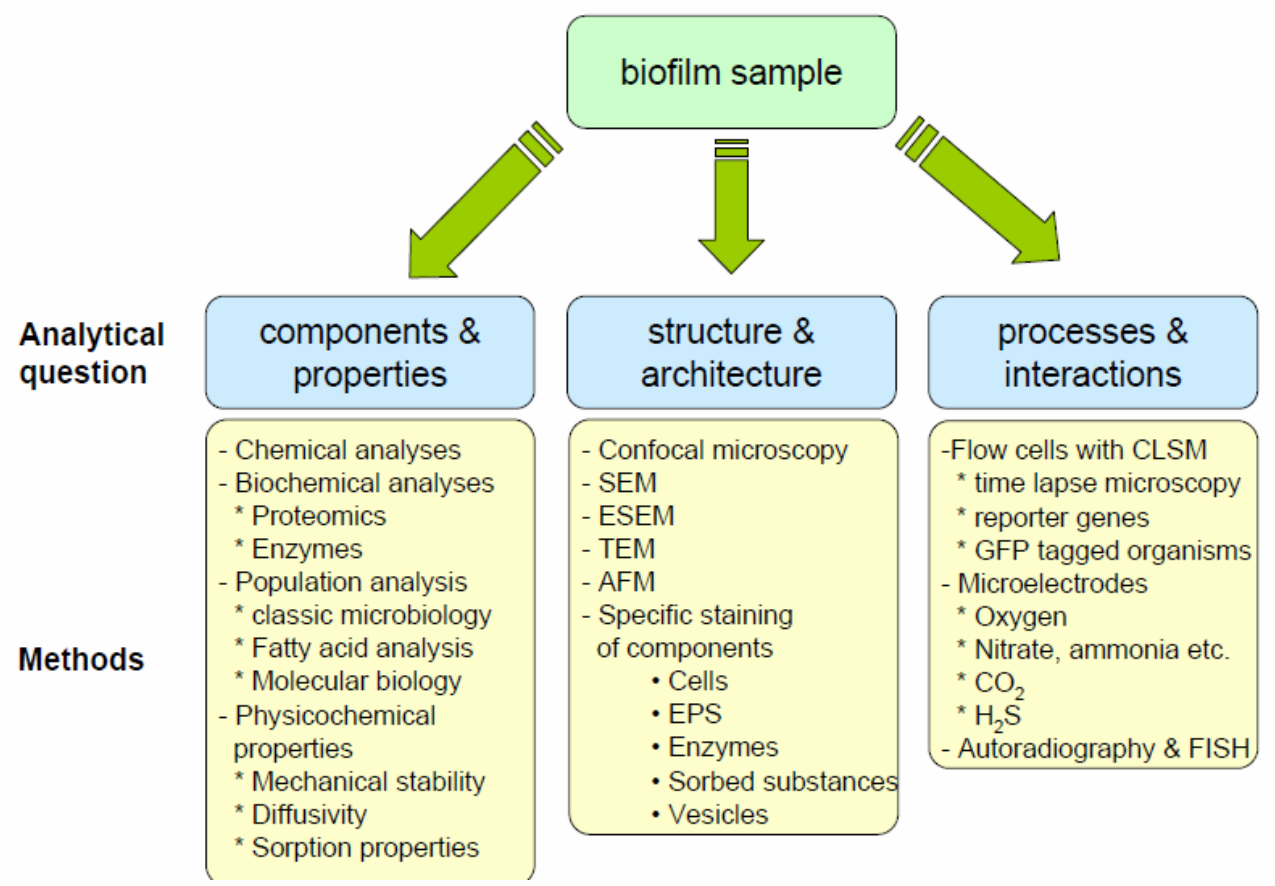

Fig. 3. Biofilm analysis

\section{Metabolic engineering of microorganisms for oligosaccharide and polysaccharide production}

Microorganisms naturally produce a wide variety of carbohydrate molecules, yet large-scale manufacturing requires production levels much higher than the natural capacities of these organisms. Metabolic engineering efforts generate microbial strains capable of meeting the industrial demand for high synthesis levels. Metabolically engineered strains have successfully produced many carbohydrate products, and many unexplored strategies, made available from recent progress in systems biology, can be used to engineer even better microbial catalysts.

For example, all species and strains of Pseudomonas are Gram-negative rods, and have historically been classified as strict aerobes. Exceptions to this classification have recently been discovered in Pseudomonas biofilms. A significant number can produce exopolysaccharides that are known as biofilms. Exopolysaccharide production contributes to surface-colonising biofilms which are difficult to remove from food preparation surfaces. Pseudomonas have the ability to metabolism a variety of diverse nutrients. Combined with the ability to form biofilms, they are thus able to survive in a variety of unexpected places (Hassett et al., 2002). 


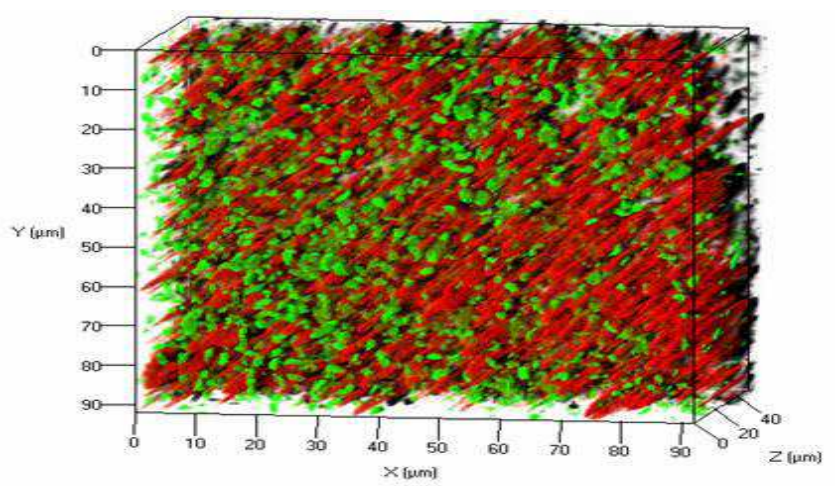

(a)

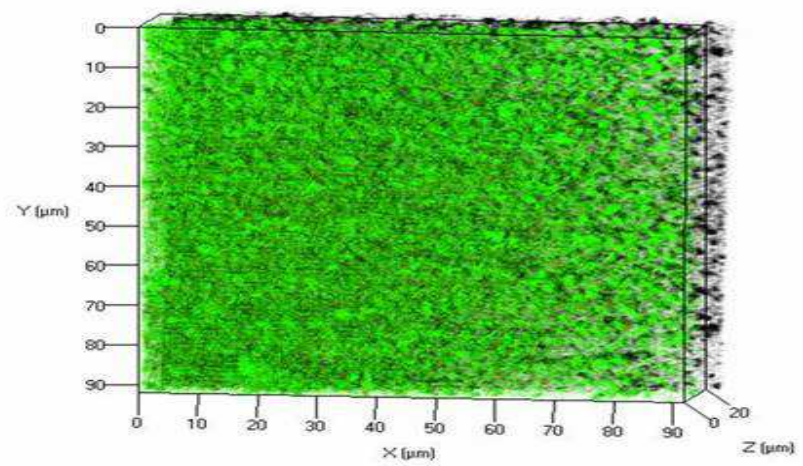

(b)

Fig. 4. Confocallaser scanning microscopy (CLSM) 3-D micrographsof a P. aeruginosa biofilm with lectin Concana valin A (red, alginate spec.) and SYTO 9 (green, cells), magnification $1000 \mathrm{x}$

P. aeruginosaSG81 (mucoid): thick(40 !m), heterogeneous biofilm, lots of alginate between cells

b) P. aeruginosa SG81R1 (non mucoid): thin $(20 ! \mathrm{m})$, unstructured biofilm, cells densely packed

\section{The role of biofilm on biocontrol of plant diseases}

The ability of biocontrol agents to control plant disease is dependent on colonization of plant surfaces. Effective colonization of plant roots by biocontrol agents plays an important role in growth promotion, irrespective of the mechanism of action (production of metabolites, production of antibiotics against pathogens, nutrient uptake effects, or induced plant resistance). It is now common knowledge that bacteria in natural environments persist by forming biofilms (Davey and O'Toole 2000). Biofilms are highly structured, surfaceattached communities of cells encased in a self-produced extracellular matrix (Costerton, 1995). Biofilm formation is a dynamic process and different mechanisms are involved in their attachment and growth. Extracellular polymeric substances play an important role in the attachment and colonization of microorganisms to food-contact surfaces. Frequently, bacteria live in the environment as biofilms, which are highly structured, surface-attached 
communities of cells encased within a self-produced extracellular polymeric substance matrix (Branda et al. 2005 and Kolter \& Greenberg 2006).
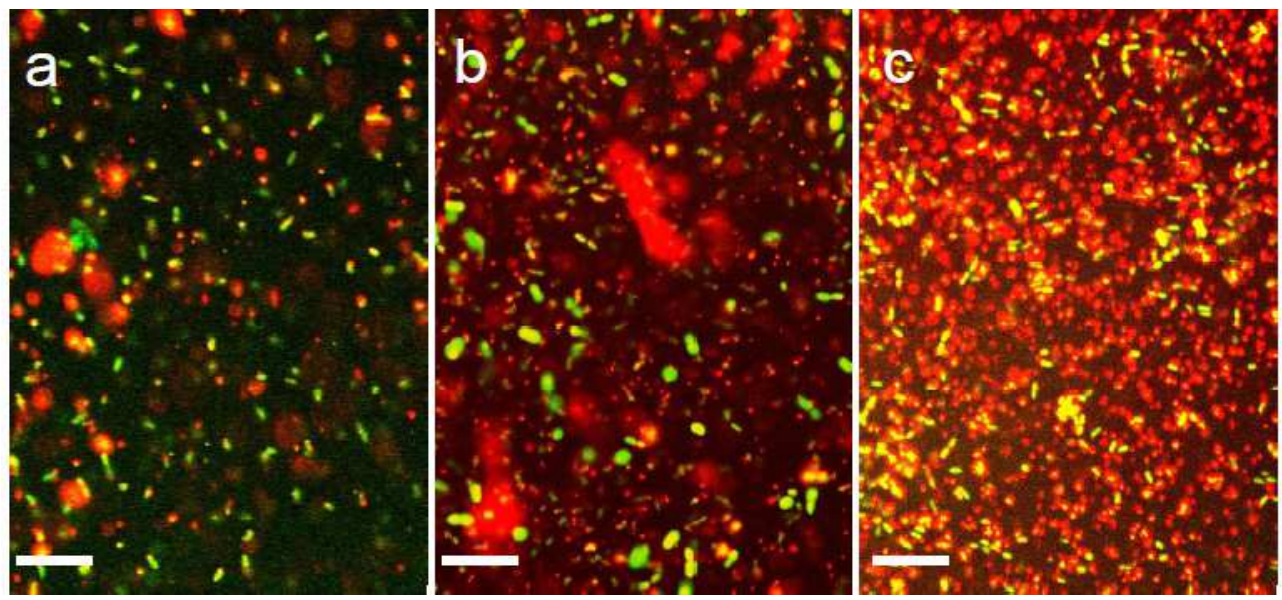

Fig. 5. edox-Enzymes demonstrated in the EPS matrix in distinct clusters Homogenous distribution in the matrix Spatia 1 and temporal heterogeneity a b c Example2: Extracellular redox enzymes Visualized by CTC reduction(red)Cells: green(SYTO 9) Bar: $10 \mu \mathrm{m}$, magnification1000 x Visualization of enzyme activity in biofilms

Various techniques have been adopted for the proper study and understanding of biofilm attachment and control. This research describes work on understanding the role of biofilm formation (process by which microbes from very large aggregates on surfaces) in the biological control of plant diseases and how this knowledge has been applied to enhance commercial biocontrol agents. Bacterial biofilms established on plant roots could protect the colonization sites and act as a sink for the nutrients in the rhizosphere, hence reducing the availability of root exudate nutritional elements for pathogen stimulation or subsequent colonization on the root (Weller and Thomashow 1994).

Beneficial plant rhizobacteria (PR) are associated with the surfaces of plant roots and may increase plant yield by mechanisms that impart improved mineral nutrient uptake, disease suppression, or phytohormone production. One beneficial rhizobacterium is Bacillus subtilis, which is ubiquitous in soil, can promote plant growth, protect against fungal pathogen attack, and play a role in the degradation of organic polymers in the soil (Emmert and Handelsman, 1999). Recently, it has been reported that B. subtilis forms adhering biofilms on inert surfaces under the control of a variety of transcription factors (Hamon and Lazazzera, 2001; Stanley et al., 2003). Kinsinger et al. (2003) and Bais et al. (2004) used infection model and they demonstrated the biocontrol ability of a wild-type B. subtilis strain 6051 against $P$. syringae. Arabidopsis root surfaces treated with $B$. subtilis were analyzed with confocal scanning laser microscopy to reveal a three-dimensional B. subtilis biofilm.

Root-associated pseudomonads have been studied extensively, and many of these promote the growth of host plants or are used as biocontrol agents (Lugtenberg et al., 2001). Pseudomonas putida can respond rapidly to the presence of root exudates in soils, converging at root colonization sites and establishing stable biofilms networks (Espinosa-Urgel et al., 
2002). Haggag, Wafaa and Salme Timmusk (2008) investigated the role of biofilm-forming Paenibacillus polymyxa strains in controlling crown root rot disease (Aspergillus niger) and highlighted importance of biofilms in biocontrol initiation. Both strains were able to suppress the pathogen but the superior biofilm former offers significantly better protection against crown rot. To make biocontrol effective and reproducible, successful colonization with the biocontrol agent must be ensured. Hence, we used SEM and solid surface assay to study colonization and biofilm formation ability of the strains (Figure 6). The strain B5 produces strikingly larger amounts of extracellular polymers (Figure 7).
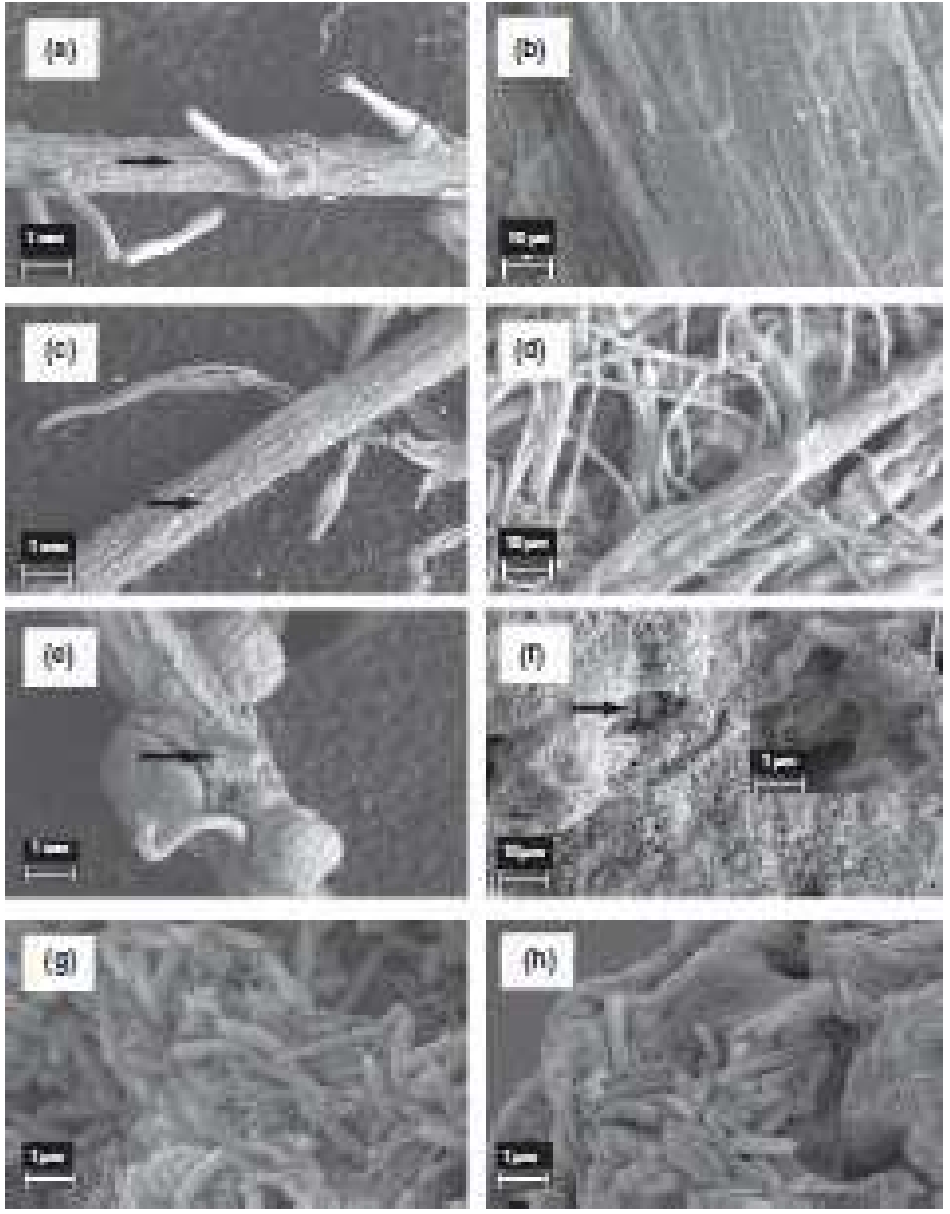

Fig. 6. Scanning electron micrographs of plant roots colonized by Paenibacillus polymyxa and Aspergillus niger (greenhouse experiment and gnotobiotic experiment). Peanut plant roots ( $a$ and $b$ ) in potting soil were infected with A. niger (c and d). Paenibacillus polymyxa B5 biofilm formation on peanut plant inhibits A. niger colonization (e and $\mathrm{f}$ ). Paenibacillus polymyxa B5 (g) and B6 (h) biofilm formation on A. thaliana root. Note that Paenibacillus polymyxa B5 isolate produces remarkably more extracellular matrix. 


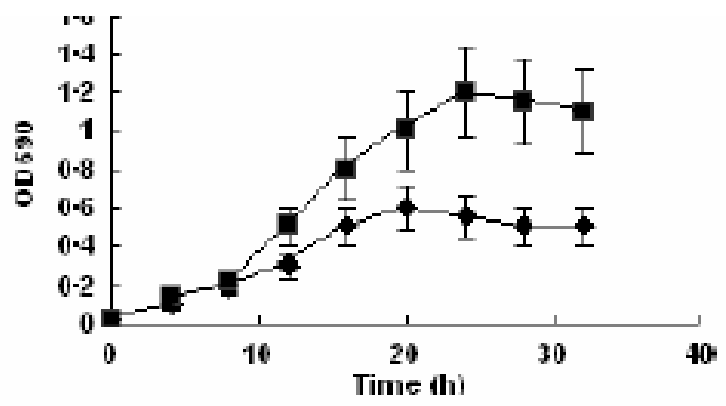

Fig. 7. Solid surface assay of Paenibacillus polymyxa B5 (r) and B6 (j) biofilm formation. The crystal violet assay was used to measure the solid surface biofilm formation at 30_C. Preparation and analysis as described in Materials and Methods.

Microorganisms often inhabit the leaf surface in organized structures termed biofilms. Burkholderia sp., FP62 is a biocontrol agent of $B$. cinerea in geranium and forms extensive biofilms in the phyllosphere. Scanning electron micrographs demonstrate extensive phyllosphere colonization (60-70\% of the leaf surface). FP62 biofilms appeared to be many cells layers thick and enveloped in a polymer-like matrix. The biofilm phenotype of this strain is related to biocontrol. Isolation of transposon mutants that are deficient in biofilm formation in an in vitro biofilm assay, also lacked the capacity to control B. cinerea when applied to geranium leaves. The biofilm mutants are less efficient in phyllosphere colonization lacking many of the characteristics of wild-type biofilms. The biofilm mutation and biocontrol capacity could be restored through the addition of exogenous polymer to the biocontrol formulation of the mutants. The addition of polymers to the formulation of several other biocontrol agents also improved their biocontrol capacity suggesting that biofilms contribute to biocontrol efficacy and are an important aspect of phyllosphere competence.

\section{Molecular genetics}

The application of molecular technologies have initiated research on biofilms focusing on the characterization of biofilm-associated genes, their exploration as a reservoir of pathogenic microorganisms, their role in antimicrobial resistance and chronic diseases, evaluation of control strategies, and development of new detection methods. The genetic manipulation of microorganisms opens up an enormous potential for the biotechnological production of biopolymers with tailored properties suitable for high-value medical application such as tissue engineering and drug delivery. Understanding the molecular mechanisms of biofilm formation has facilitated the exploration of novel strategies to control bacterial biofilms.

Technological progress in microscopy, molecular genetics, genome analysis has significantly used for understanding of the structural and molecular aspects of biofilms, especially of extensively studied model organisms such as Pseudomonas aeruginosa. Biofilm development was divided into several key steps including attachment, microcolony formation, biofilm maturation and dispersion; and in each step bioagent may recruit different components and molecules including flagellae, type IV pili, DNA and exopolysaccharides .

Biofilms are also an ideal place for exchanging genetic material and maintaining a large and accessible gene pool. Horizontal gene transfer is facilitated, since the cells are maintained in 
close proximity to each other, are not fully immobilized, and can exchange genetic information. In 1999, Hausner and Wuertz reported significantly higher rates of conjugation in bacterial biofilms than in planktonic populations (Hausner and. Wuertz. 1999). High rates of conjugation in bacterial biofilms as determined by quantitative in-situ analysis. (AllesenHolm et al., 2006) found that in P. aeruginosa biofilms, the e-DNA is likely derived from whole genomic DNA. Surprisingly, e-DNA was organized in distinct patterns in the biofilms of this organism, forming grid-like structures, suggesting a structural role for eDNA. Yang et al. (2007) also found that e-DNA was one of the major matrix components in $P$. aeruginosa biofilms, functioning as an intercellular connector; they supported the concept of the stabilizing role of e-DNA for the biofilm matrix. In P. aeruginosa, the release of e-DNA is under the control of quorum-sensing systems as well as iron regulation (Yang, et al., 2007). Stanley et al. (2003) studied biofilms structured of Bacillus subtilis used DNA microarrays They identified 519 genes that were differentially expressed at one or more time points as cells transitioned to a biofilm. Approximately $6 \%$ of the genes of $B$. subtilis were differentially expressed at a time when $98 \%$ of the cells in the population were in a biofilm. These genes were involved in motility, phage-related functions, and metabolism. By comparing the genes differentially expressed during biofilm formation with those identified in other genomewide transcriptional-profiling studies, they were able to identify several transcription factors whose activities appeared to be altered during the transition from a planktonic state to a biofilm (Figure 8). Two of these transcription factors were Spo0A and sigma-H, which had previously been shown to affect biofilm formation by B. subtilis. A third signal that appeared to be affecting gene expression during biofilm formation was glucose depletion.

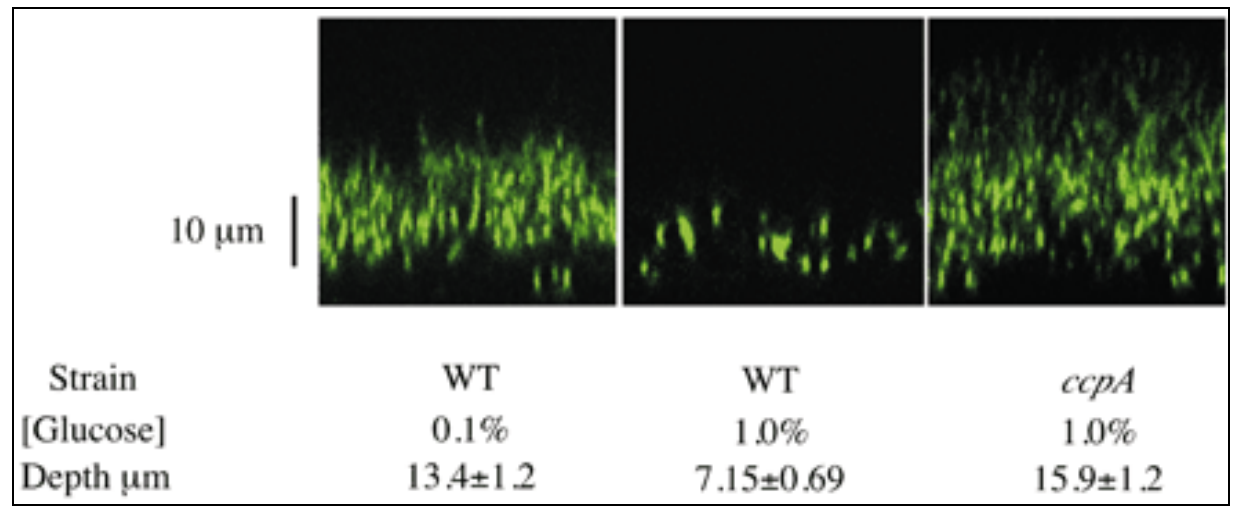

Fig. 8. Effect of catabolite repression on the structure of B. subtilis biofilms. Shown are representative CSLM images of biofilms of $B$. subtilis expressing GFP in the $x z$ plane. The depth of biofilm ( \pm standard error of the mean), calculated from a minimum of three independent experiments, is indicated. WT, strain BAL218; ccpA, strain BAL795.

P. fluorescens ' $1100-6$ ' was genetically tagged to allow exploration of its localization in grapevines (Eastwell et al., 2006). In growth chamber studies, P. fluorescens '1100-6' was found to survive in the rhizoplane of grapevines for 6 months. Microscopic examination showed that the genetically modified $P$. fluorescens ' $1100-6$ ' predominantly occupied xylem and pith tissues, and occasionally persisted on external surfaces of grapevines (Figure 9). 
The role of extracellular polymers in biofilm formation was studied using three mutants of Sphingomonas paucimobilis with increasing capabilities for exopolymer production. The physical, biochemical and physiological properties of three different layers of each biofilm were determined. The layers were detached by submitting the biofilm to increasing shear stress. The results revealed that the presence of exopolymers in the growth medium was essential for biofilm formation. The mutant producing the highest amount of exopolymer formed very thick biofilms, while the biofilms formed by the medium exopolymer producer were on average 8 times thinner. The lowest exopolymer producer did not form biofilm. In both types of biofilms, exopolymer density increased with depth, although this tendency was more significant in thinner biofilms. Cell distribution was also more heterogeneous in thinner biofilms, exhibiting a greater accumulation of cells in the inner layers. The thicker biofilms had very low activity in the inner layer. This was related to a high accumulation of proteins and DNA in this layer due to cell lysis and hydrolytic activity. Activity in the thin biofilm was constant throughout its depth, suggesting that there was no nutrient limitation. The production of exopolymers by each cell was constant throughout the depth of the biofilms, although it was greater in the case of the higher producer.
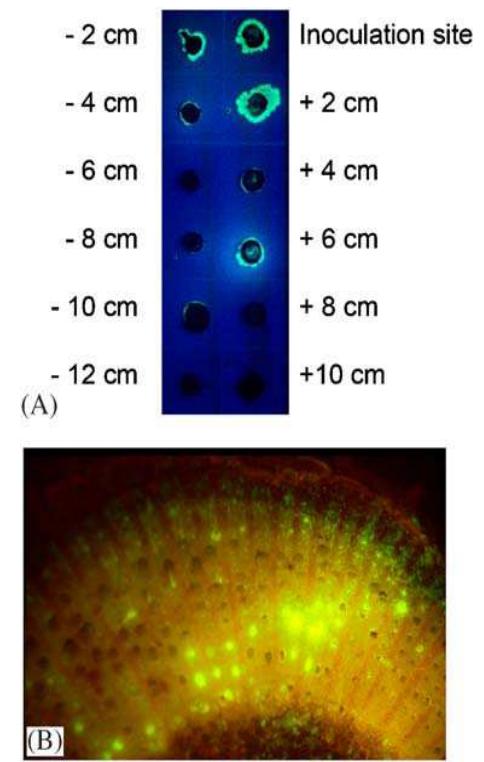

Fig. 9. Detection of the green-fluorescent-protein from the genetically tagged biocontrol agent Pseudomonas fluorescens isolate 1100-6 (P. fluorescens '1100-6-gfp') in grapevines 6 onths after stem inoculation using a bullet-piercing valve. (A) Fluorescence surrounding tissues sections after incubation on nutrient agar medium. Tissue sections were taken at 2 cm intervals acropetally $(+)$ and basipetally from the inoculation site. Sections are observed under black light after growth on nutrient agar for 2 days. The P. fluorescens '1100-6-gfp' diffused out of the tissue sections and was evident by green fluorescent areas surrounding the sections. (B) A section of grapevine taken $2 \mathrm{~cm}$ above the point of injection and observed with an epifluorescent microscope. The green fluorescence in the xylem vessels is indicative of the presence of the gfp-gene product. 


\section{Conclusion}

The use of microorganisms to control plant diseases offers an attractive alternative to the use of synthetic chemicals. In accordance, the diversity of microbial communities provides a rich source of potential biocontrol agents. The abundance of a beneficial strain of microorganism in the vicinity of plant roots may suppress plant pathogens without producing lasting effects on the rest of the soil microbial and plant communities. Biofilms serve as a new model system for the study of microbial development providing insights into microbial biology and ecology. One of the keys to studying complex biological systems is to develop accurate and realistic models of natural communities in the laboratory. Currently, many of these effects can only be speculated upon, although application of novel probes and improved analytical methods will gradually expand on our current, rather limited, and perhaps blinkered view of what biofilm structures really are and the extent to which they are determined by EPS. Their ability to interact with other polysaccharides and with other macromolecules and cells, as well as with ions and low-molecular-mass solutes, provide a multitude of microenvironments within any biofilm.

\section{References}

Allesen-Holm, M., Barken, K. B., Yang, L., Klausen, M., Webb, J. S., Kjelleberg, S., Molin, S., Givskov, M. and Tolker-Nielsen. T. (2006). A characterization of DNA release in Pseudomonas aeruginosa cultures and biofilms. Mol. Microbiol. 59:1114-1128.

Bais, H., Ray Fall and Jorge M. V. (2004). Biocontrol of Bacillus subtilis against Infection of Arabidopsis Roots by Pseudomonas syringae Is Facilitated by Biofilm Formation and Surfactin Production. Plant Physiology 134:307-319 .

Bianciotto, V., Andreotti, S., Balestrini, R., Bonfante, P. and Perotto S. (2004). Mucoid mutants of the biocontrol strain Pseudomonas fluorescens CHA0 show increased ability in biofilm formation. Current Opinion in Microbiology, 7:602-609.

Branda, S.S., Vik, S., Friedman, L. and Kolter, R. (2005). Biofilms: the matrix revisited. Trends Microbiol 13, 20-26.

Costerton, J. W. (1995). Overview of microbial biofilms. J. Ind. Microbiol. 15:137-140

Davey, M. E., and O'Toole, A. G. (2000). Microbial biofilms: from ecology to molecular genetics. Microbiol. Mol. Biol Rev. 64:847-867

Emmert, E.A.B. and Handelsman, J. (1999) Biocontrol of plant disease: a Gram-positive perspective. FEMS Microbiol Lett 171: 1-9

Eastwell, K.C., Sholberg, P.L. and Sayler R.J. (2006). Characterizing potential bacterial biocontrol agents for suppression of Rhizobium vitis, causal agent of crown gall disease in grapevines. Crop Protection. 25:1191-1200

Espinosa-Urgel, M., Kolter, R. and Ramos, J.L. (2002). Root colonization by Pseudomonas putida: love at first sight. Microbiology 148:341-343.

Friedman, L. and Kolter, R. (2004). Genes involved in matrix formation in Pseudomonas aeruginosa PA14 biofilms. Mol. Microbiol, 51:675-690. 
Frølund, B., Palmgren, R. Keiding, K. and Nielsen, P. H. (1996). Extraction of extracellular polymers from activated sludge using a cation exchange resin. Water Res. 30:17491758.

Gage D.J. (2004). Infection and invasion of roots by symbiotic, nitrogen-fixing rhizobia during nodulation of temperate legumes. Microb Mol Biol Rev, 68:280-300.

Haggag, Wafaa, M. (2007). Colonization of exopolysaccharide-producing Paenibacillus polymyxa on peanut roots for enhancing resistance against crown rot disease . African Journal of Biotechnology, 6 (13): 1568-1577.

Haggag, Wafaa, M. and Salme Timmusk (2008). Colonization of peanut roots by biofilmforming Paenibacillus polymyxa initiates biocontrol against crown rot disease. Journal of Appl Microbiol. 104 ( 4 ): 961-969.

Hall-Stoodley, L., Costerton, J.W. and Stoodley, P. (2004). Bacterial biofilms: from the natural environment to infectious diseases. Nature Reviews. Microbiology 2 (2): 95108

Hassett, D., Cuppoletti, J., Trapnell , B., Lymar, S., Rowe, J., Yoon, S., Hilliard, G., Parvatiyar, K., Kamani, M., Wozniak, D., Hwang, S., McDermott, T. and Ochsner, U. (2002). "Anaerobic metabolism and quorum sensing by Pseudomonas aeruginosa biofilms in chronically infected cystic fibrosis airways: rethinking antibiotic treatment strategies and drug targets". Adv Drug Deliv Rev. 54 (11): 1425-43.

Hausner, M., and S. Wuertz. (1999). High rates of conjugation in bacterial biofilms as determined by quantitative in-situ analysis. Appl. Environ. Microbiol. 65:3710-3713.

Karatan, E.and Watnick, P. (2009). Signals, regulatory networks, and materials that build and break bacterial biofilms. Microbiology and Molecular Biology Reviews : MMBR 73 (2): 310-47

Kinsinger, R.F., Shirk, M.C. and Fall , R. (2003) Rapid surface motility and biofilm formation in Bacillus subtilis is dependent on extracellular surfactin and potassium ion. J Bacteriol 185: 5627-5631

Kolter, R. and Greenberg, E.P. (2006) Microbial sciences: the superficial life of microbes. Nature 441, 300-302.

Lugtenberg, B.J.J., Dekkers, L. and Bloemberg, G.V. (2001). Molecular determinants of rhizosphere colonization by Pseudomonas. Annu Rev Phytopathol 39:461-490.

Ma, L., K. D. Jackson, R. M. Landry, M. R. Parsek, and D. J. Wozniak. (2006). Analysis of Pseudomonas aeruginosa conditional Psl variant reveals roles for the Psl polysaccharide in adhesion and maintaining biofilm structure postattachment. J. Bacteriol. 188:8213-8221.

Ramey B.E., Matthysse A.G., Fuqua C. (2004). The FNR-type transcriptional regulator SinR controls maturation of Agrobacterium tumefaciens biofilms. Mol Microbiol. 52:14951511.

Stanley N.R., Britton RA, Grossman A.D, Lazazzera BA (2003) Identification of catabolite repression as a physiological regulator of biofilm formation by Bacillus subtilis by use of DNA microarrays. J Bacteriol 185: 1951-1957

Weller, D.M. and Thomashow, L.S. (1994). Current challenges in introducing beneficial microorganisms into the rhizosphere. In Molecular Ecology of Rhizosphere 
Microorganisms ed. O'Gara, F., Dowling, D.N. and Boesten, B. pp. 1-18.NY: Academic Press.

Yang, L., K. B. Barken, M. E. Skindersoe, A. B. Christensen, M. Givskov, and T. TolkerNielsen. (2007). Effects of iron on DNA release and biofilm development by Pseudomonas aeruginosa. Microbiology 153:1318-1328. 


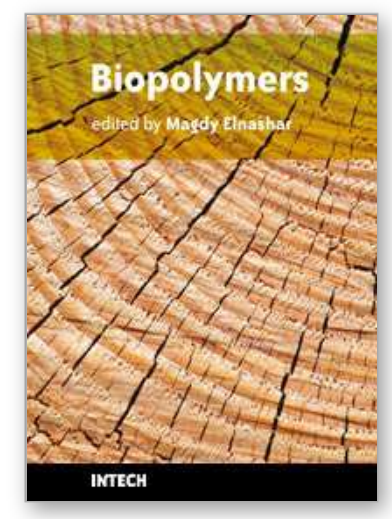

\author{
Biopolymers \\ Edited by Magdy Elnashar
}

ISBN 978-953-307-109-1

Hard cover, 612 pages

Publisher Sciyo

Published online 28, September, 2010

Published in print edition September, 2010

Biopolymers are polymers produced by living organisms. Cellulose, starch, chitin, proteins, peptides, DNA and RNA are all examples of biopolymers. This book comprehensively reviews and compiles information on biopolymers in 30 chapters. The book covers occurrence, synthesis, isolation and production, properties and applications, modification, and the relevant analysis methods to reveal the structures and properties of some biopolymers. This book will hopefully be of help to many scientists, physicians, pharmacists, engineers and other experts in a variety of disciplines, both academic and industrial. It may not only support research and development, but be suitable for teaching as well.

\title{
How to reference
}

In order to correctly reference this scholarly work, feel free to copy and paste the following:

Wafaa Haggag (2010). The Role of Biofilm Exopolysaccharides on Biocontrol of Plant Diseases, Biopolymers, Magdy Elnashar (Ed.), ISBN: 978-953-307-109-1, InTech, Available from:

http://www.intechopen.com/books/biopolymers/the-role-of-biofilm-exopolysaccharides-on-biocontrol-of-plantdiseases

\section{INTECH}

open science | open minds

\section{InTech Europe}

University Campus STeP Ri Slavka Krautzeka 83/A 51000 Rijeka, Croatia Phone: +385 (51) 770447

Fax: +385 (51) 686166 www.intechopen.com

\section{InTech China}

Unit 405, Office Block, Hotel Equatorial Shanghai No.65, Yan An Road (West), Shanghai, 200040, China 中国上海市延安西路65号上海国际贵都大饭店办公楼405单元 Phone: +86-21-62489820

Fax: +86-21-62489821 
(C) 2010 The Author(s). Licensee IntechOpen. This chapter is distributed under the terms of the Creative Commons Attribution-NonCommercialShareAlike-3.0 License, which permits use, distribution and reproduction for non-commercial purposes, provided the original is properly cited and derivative works building on this content are distributed under the same license. 